\title{
EFFECT OF SIMULATOR TRAINING ON DRIVING AFTER STROKE: A RANDOMIZED CONTROLLED TRIAL
}

\author{
Abiodun Emmanuel Akinwuntan, Willy De Weerdt, Hilde Feys, Jan Pauwels \\ Department of Rehabilitation Sciences \\ Faculty of Kinesiology and Rehabilitation Sciences \\ Katholieke Universiteit Leuven \\ Belgium \\ Guido Baten, Patricia Arno \\ CARA \\ Belgian Road Safety Institute \\ Brussels, \\ Belgium \\ Carlotte Kiekens \\ Department of Physical Medicine and Rehabilitation \\ University Hospital Pellenberg \\ Katholieke Universiteit Leuven \\ Belgium \\ E-mail: aakinwuntan@yahoo.com
}

\section{PAPER NOT AVAILABLE}

\begin{abstract}
Summary: Neurologically impaired persons seem to benefit from driving training programs, but there is no convincing evidence to support this notion. We therefore investigated the effect of simulator-based training on driving after stroke. Eighty-three first ever sub-acute stroke patients entered a 5-week, 15-hour training program in which they were randomly allocated to either an experimental (simulator-based training) or control (driving-related cognitive tasks) group. Performance in off-road evaluations and an on-road test were used to assess the driving ability of subjects pre- and post-training. Outcome of an official predriving assessment administered 6 to 9 months post stroke were also considered. Both groups significantly improved in a visual and many neuropsychological evaluations and in the on-road test after training. There were no significant differences between both groups in improvements from pre- to post-training except in the "road sign recognition test," in which the experimental subjects improved more. Statistically significant improvements in the three-class decision ("fit to drive," "temporarily unfit to drive" and "unfit to drive") were found in favor of the experimental group. Academic qualification and overall disability together determined subjects who benefited most from the simulator-based driving training. Significantly more experimental subjects (73\%) than controls (42\%) passed the follow-up official pre-driving assessment and were legally allowed to resume driving. We concluded that simulator-based driving training was a better method, especially for well educated and less disabled stroke
\end{abstract}


patients. However, the findings of the study may have been modified as a result of the large number of dropouts and the possibility of some neurological recovery unrelated to training.

\section{ACKNOWLEDGMENTS}

The primary author expresses profound appreciation to the Belgian Institute for Road Safety, Brussels, Belgium, particularly the CARA section, for their usual cooperation and support. The author also acknowledges the Interfaculty Council for Development Co-operation Scholarships Programme of the Katholieke Unversiteit Leuven, Belgium, for funding support of his doctoral education.

Finally, the primary author is extremely grateful to the other institutions where he worked (School of Health and Bioscience, University of East London, London, United Kingdom) and is currently working (School of Allied Health Sciences, Medical College of Georgia, Augusta, GA, USA) for all the funds and other resources that have been expended to ensure successful attendance and presentation at the symposium.

\section{Supplier}

The original and full version of this paper can be found in the August 2005 edition of the journal of NEUROLOGY. 